\title{
Imaging techniques in nanomedical research
}

\author{
Laura Calderan, Manuela Malatesta
}

Department of Neurosciences, Biomedicine and Movement Sciences, Anatomy and Histology Section, University of Verona, Italy

\begin{abstract}
About twenty years ago, nanotechnology began to be applied to biomedical issues giving rise to the research field called nanomedicine. Thus, the study of the interactions between nanomaterials and the biological environment became of primary importance in order to design safe and effective nanoconstructs suitable for diagnostic and/or therapeutic purposes. Consequently, imaging techniques have increasingly been used in the production, characterisation and preclinical/clinical application of nanomedical tools. This work aims at making an overview of the microscopy and imaging techniques in vivo and in vitro in their application to nanomedical investigation, and to stress their contribution to this developing research field.
\end{abstract}

Key words: Electron microscopy; histochemistry; light microscopy; magnetic resonance imaging; nanoparticles; optical imaging.

Correspondence: Manuela Malatesta, Department of Neurosciences, Biomedicine and Movement Sciences, Anatomy and Histology Section, University of Verona, Strada Le Grazie 8, 37134 Verona, Italy.

Tel. +39.045.8027569.

E-mail: manuela.malatesta@univr.it 


\section{Introduction}

Since the Nineties of the last Century, nanotechnology began to be applied to biomedical issues, giving rise to a new research field called nanomedicine. ${ }^{1}$ Until that time, the development of nanomaterials had been almost exclusively the prerogative of chemists and physicists who obviously mostly used physico-chemical methods to characterise new nanoproducts. With the advent of nanomedicine, the interactions between nanomaterials and the biological environment -from the single cell to the whole organismbecame of paramount importance in order to set up safe and effective nanoconstructs suitable for diagnostic and/or therapeutic purposes. Consequently, imaging techniques have been increasingly used in the production, characterisation and preclinical/clinical application of nanomedical tools, ${ }^{2-5}$ taking advantage from the great improvement and evolution imaging techniques have experienced in biomedical research and clinical applications, especially in the years 2000 .

In vivo imaging techniques (e.g., magnetic resonance imaging, optical imaging) have been applied in studies aimed at investigating the targeting, biodistribution and clearance of the nanoconstructs in the whole organism with a view in the short, medium and long time. Light and electron microscopy have mostly been used to evaluate the impact of new nanoparticles (NPs) in single cells, in order to understand the internalisation efficacy and mechanisms, intracellular fate and relationships with cell organelles; moreover, microscopy proved to be useful to track NPs in tissues and organs. Both in vitro and in vivo studies have been combined in many researches $\left(e . g .{ }^{6-14}\right)$ and proved to be crucial to characterise novel nanocarriers and design proficient and safe strategies for their use in nanomedicine.

The present paper aims at browsing the scientific literature of the last decade to get an overview of the microscopy and imaging techniques in their application to nanomedical investigation, and to evaluate their contribution to this recent and developing research field.

It is worth noting that the number of articles in qualified journals on the application of nanoconstructs in biology and medicine has dramatically increased since 2000 , but the percentage of papers where imaging and microscopy techniques were used has constantly ranged between $20-25 \%$ (Figure 1 ).

\section{Imaging techniques applied to in vivo models}

In the last decades, in vivo imaging devices have become fundamental tools in basic sciences, in preclinical research and in modern drug development to visualize nanocomposites. The most suitable and commonly used techniques are magnetic resonance imaging (MRI), optical imaging (OI), positron emission tomography (PET) ${ }^{15}$ computed tomography and ultrasonography, ${ }^{16}$ and a number of recent articles focused on the visualization of nanoconstructs by these approaches in a biological environment.

Madru et al. ${ }^{17}$ proposed new hybrid superparamagnetic iron oxide NPs labelled with ${ }^{64} \mathrm{Cu}$ for PET/MRI in vivo imaging, to be detected and located in sentinel lymph nodes where the presence of metastases is an important marker for cancer staging and treatment: through a biodistribution study, the authors demonstrated the stability of radiolabelling up to $24 \mathrm{~h}$ and NPs accumulation in the sentinel lymph nodes.

Magnetic NPs with an iron core have been used in MRI for more than twenty years as contrast agents with a particular affinity toward specific organs and tissues, ${ }^{18}$ and more recently they have also been applied as effective agents in hyperthermic therapy mainly in tumour pathology. ${ }^{19-22}$ Quantum dots are both fluorescent and magnetic NPs, thus being suitable tools for protocols of both OI and MRI in vivo. Through OI acquisitions, very small quantity of quantum dots can be detected and located, while MRI allows extrapolating a detailed morphological information of the anatomical sites where they accumulate. ${ }^{13} \mathrm{New}$-generation quantum dots have specifically been used for fluorescent imaging in the field of drug discovery ${ }^{23,24}$ and in the functional imaging (e.g., detailed three-dimensional quantitative flow maps of the brain vasculature were obtained using these quantum dots ${ }^{25}$ ).

Fluorescent imaging techniques proved to be also suitable for studying in vivo solid lipid NPs that are very advantageous nanoconstructs for their biocompatibility and low toxicity, ${ }^{12,14}$ and can be used as nanocarriers being easily targeted and able to cross the blood brain barrier. ${ }^{26}$

Nanoscale highly echogenic agents for imaging and ultrasound-mediated drug delivery were developed by Perera et al. ${ }^{27}$ who demonstrated by in vivo ultrasound analysis and fluorescencemediated tomography that these innovative NPs exhibit greater tumour extravasation and accumulation than classical microbubbles, thus having great potential for diagnostics and drug delivery.

More than one imaging technique has often been simultaneously used in multimodal imaging protocols in vivo. ${ }^{13,28-31}$ In this approach, different techniques are selected according to the chemical and physical characteristics of the nanocompounds under study. For instance, radiolabelled molecules such as ${ }^{18} \mathrm{~F}$-flurodeoxyglucose $\left({ }^{18} \mathrm{~F}-\mathrm{FDG}\right)$ may be used as bimodal tracers for PET and for OI based on the Cerenkov radiation emission: this was demonstrated by Boschi and colleagues $^{32}$ in an experimental mouse model of mammary carcinoma, where similar images of the ${ }^{18} \mathrm{~F}-\mathrm{FDG}$ biodistribution (indicative of the glucose metabolism) in different organs were obtained using PET scanner and Cerenkov OI.
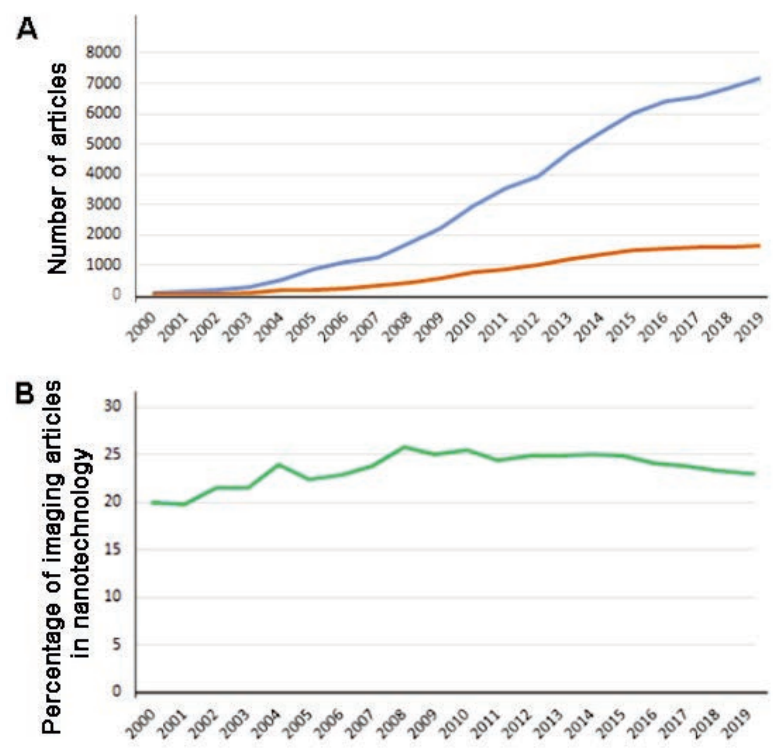

Figure 1. A) Total number of published articles on nanotechnology applied to the biomedical field (blue line) and articles on nanotechnology where imaging or microscopy techniques were used (red line), in the years 2000-2019; B) percentage of articles where imaging techniques were used. Data were taken from the Web of Science database. 
The interesting study by Sulheim and colleagues is another example of multimodal imaging: ${ }^{33}$ the authors investigated the organization and density of functional blood vessels that newly developed in a tumour tissue by intense angiogenesis. Actually, angiogenesis is crucial to understand how tumour heterogeneity affects the uptake and accumulation of therapeutic agents (among which NPs in nanomedical therapy). In this investigation, three different in vivo imaging techniques were used (i.e., micro-computed tomography, contrast-enhanced ultrasound, and diffusionweighted and dynamic contrast-enhanced MRI) and the authors demonstrated that NP accumulation depends on the extent of the tumour vasculature as wells as on the morphology and perfusion of the vessels.

The in vivo imaging techniques are also powerful and irreplaceable tools for tracking and monitoring the so-called theranostic NPs, i.e., the multifunctional nanosystems where the diagnostic and therapeutic capabilities are combined into one single biocompatible nanoconstruct. ${ }^{34}$

Qiu and coauthors ${ }^{35}$ developed multifunctional theranostic NPs based on gold nanocages (AuNCs) modified with hyaluronic acid and functionalized with anti-Glypican-1 antibody, oridonin, gadolinium, and $\mathrm{Cy} 7$ dye for accurate diagnosis and effective treatment of pancreatic cancer. With an imaging longitudinal study in vivo, the authors monitored the biodistribution of the nanoconstructs and, at the same time, the evolution of a nano-mediated therapy as well as the morphological and functional modifications of the diseased tissues and organs. Kwak and colleagues ${ }^{36}$ studied a specific dodecapeptide probe as a promising candidate for both colon tumour diagnosis and targeted drug delivery: fluorescently labelled NPs loaded with this peptide conjugated to a photosensitizer showed a significantly enhanced cellular uptake and high photodynamic effect to kill tumour cells in tumour-bearing mice.

Gawne and collegues ${ }^{37}$ set up the encapsulation of glucocorticoids into long-circulating liposomes to reduce the side effects of glucocorticoids and improve the treatment of inflammatory diseases; these nanoconstructs were radiolabelled thus allowing the characterization and tracking in an in vivo model using PET imaging for a theranostic approach.

\section{Imaging techniques applied to in vitro models}

The most common imaging technique applied to detect NPs inside cultured cells and tissues is fluorescence microscopy (FM). In particular, confocal FM (CFM) has widely been used in parallel with physico-chemical analyses, to demonstrate the efficacy of novel nanoconstructs in cell targeting and drug delivery, frequently using established cancer cell lines.

The capability of polyamidoamine dendrimers, ${ }^{38}$ or nanosized polyethylenimine complexes ${ }^{39}$ to deliver antisense oligonucleotides as well as of polyethylenimine-hexametaphosphate NPs to carry nucleic-acid-based therapeutics ${ }^{40}$ to tumour cells was evaluated by CFM. The same technique was also used to test the uptake efficacy of solid lipid NPs aimed at HIV prevention, ${ }^{41}$ silica NPs for tumour targeting, ${ }^{42,43}$ or avidin-conjugated calcium phosphate $\mathrm{NPs}^{10}$ and AuNCs for harnessing imaging and hyperthermia therapy of cancer. ${ }^{44} \mathrm{CFM}$ gave information also on the functionalization efficacy in increasing quantum dots uptake by cancer cells. ${ }^{45}$ The internalization mechanisms of gold nanoclusters, intended as fluorescent nanoprobes for bio-imaging and related applications in cancer treatment, were investigated by CFM in cell culture models of tumour and non-tumour cells. ${ }^{46} \mathrm{CFM}$ allowed testing the efficacy of paclitaxel-loaded expansile NPs in a mesothelioma spheroid model, ${ }^{47}$ the uptake and distribution of nanodiamonds in different cell lines and organ slices, ${ }^{48}$ and the ability of Pullulan acetate NPs to pass the placental barrier in in vitro cell monolayers. ${ }^{49}$

Furthermore, CFM was frequently used in combination with other imaging/microscopy techniques.

CFM and flow cytometry have been associated to investigate the mechanism of dendrimers uptake,,$^{50}$ as well as the internalization efficacy of zein/carboxymethyl chitosan NPs as delivery vehicles for drugs or nutrients. ${ }^{51}$ The same approach was used to test PEGylated $\mathrm{NPs}^{52}$ and cyclodextrin-based $\mathrm{NPs}^{6}$ for enhanced tumour cell internalization and cytotoxicity, or gold nanoclusters for fluorescence imaging and enhanced drug transport, ${ }^{53}$ or poly(lactide-co-glycolide) NPs for protein delivery to macrophages. ${ }^{54}$ Combination of CFM and flow cytometry also allowed understanding the effect of functionalization on the uptake of dense-silica NPs by gastric cancer cells,${ }^{8}$ or the influence of anaesthetics on the internalization efficacy of dendrimers by microglial cells..$^{55}$

The uptake efficacy of poly (lactic-co-glycolic acid)poly(ethylene-glycol)-folate NPs was studied in cancer cell culture combining CFM, flow cytometry and MRI, ${ }^{9}$ while superparamagnetic iron oxide NPs were visualised inside the cells with CFM and MRI. ${ }^{56}$

The endocytosis pathways, intracellular fate and release of polystyrene $\mathrm{NPs}^{57}$ and multifunctional NP-EpCAM aptamer bioconjugates ${ }^{58}$ were investigated by combining CFM and spectrofluorometric/spectrophotometric analyses, and the internalisation of carboxyl-coated quantum dots was studied by CFM and steadystate fluorescence spectroscopy..$^{59} \mathrm{By}$ using CFM in combination with traction force microscopy, the capacity of cultured cells of internalising NPs was related to the mechanical stress. ${ }^{60}$

To better elucidate the internalisation mechanisms and intracellular pathway of NPs and their impact on cell organelles, a higher resolution is needed than the one of light microscopy. Consequently, many studies on NPs were performed by transmission electron microscopy (TEM) or scanning transmission electron microscopy (STEM). TEM was used to investigate the uptake by a human cell line of gold NPs prepared in aqueous biocompatible solution, ${ }^{61}$ while the internalization of chitosan-functionalized gold NPs was assessed by combining TEM and electron energy loss spectroscopy. ${ }^{62}$ TEM and inductively coupled plasma mass spectrometry were employed to visualize and quantify the internalization and distribution of gold NPs for drug delivery and imaging diagnostics in isolated endothelial cells and whole vessels. ${ }^{63}$ STEM and electron tomography were crucial to demonstrate that the particle size affects the ability of functionalized platinum NPs to escape the endo-lysosomal pathway. ${ }^{64}$

High-resolving electron microscopies (TEM and SEM) have increasingly been associated with other imaging/microscopy techniques in nanomedical research to analyse the intracellular fate of NPs.

FM, CFM and TEM were used to investigate the tumour cell uptake of different biocompatible NPs, ${ }^{65-67}$ drug-gold NP conjugates incorporated into liposomes, ${ }^{68}$ phospholipidic manganese-based NPs ${ }^{69}$ nickel nanowires,${ }^{70}$ and magnetic NPs. ${ }^{71}$ CFM and TEM were also combined to investigate the lipolytic potential of superparamagnetic iron oxide hyperthermic NPs, ${ }^{72}$ the capability of cycling and non-cycling muscle cells to internalise different biocompatible NPs, ${ }^{73,74}$ and the ability of drug-loaded gold NPs to target macrophages and fibroblasts to treat lung fibrosis. ${ }^{75}$ The influence of a static magnetic field on the delivery of magnetic NPs was investigated by combining CFM, TEM and SEM. ${ }^{76}$ The uptake efficiency of surface-active maghemite NPs was assesses in mesenchymal stromal cell by using bright-filed microscopy, flow cytometry, SEM and atomic force microscopy (AFM) ${ }^{77}$ Sphero magnetic NPs were detected in a multicellular neural model by using time-lapse phase contrast microscopy, CFM, TEM and SEM. ${ }^{78}$ The intracellular fate of 
superparamagnetic NPs intended for nanothermal ablation and MRI contrasting was investigated by phase contrast, CFM and TEM. ${ }^{79}$ Bright-field microscopy, FM and TEM allowed describing the cell and tissue distribution of solid lipid NPs. ${ }^{14}$

The study of the NP uptake and intracellular fate in cultured cells has sometimes been performed by specially designed imaging techniques. As an example, penetration of gold nanoshells into 3D cell culture was evaluated using hyperspectral imaging with dark field microscopy. ${ }^{80}$ Moreover, radiolabelled superparamagnetic NPs intended as a new contrast agent for multimodal imaging were detected in mouse mesenchymal stem cells by in vitro PET/MRI. ${ }^{11}$

The detection of NPs in the cell or tissue milieu may be sometimes problematic, especially when the nanoconstructs are made of organic material. To overcome this limit, specific histochemical techniques proved to be suitable. The iron-specific Prussian blue staining has been the method of choice to visualize superparamagnetic iron oxide NPs at bright-field microscopy, ${ }^{81}$ sometimes in association with MRI, ${ }^{39,82} \mathrm{CFM},{ }^{83} \mathrm{TEM}^{84}$ or SEM and AFM. ${ }^{77}$ Gold NPs were detected and quantified at bright-field microscopy by silver-enhancement staining. ${ }^{80}$ Diaminobenzidine photo-oxidation was appropriate to correlate FM and TEM with the aim of precisely tracking the NPs intracellular fate. ${ }^{65,66,69,85}$ Recently, the Alcian blue staining has been used to detect hyaluronic-acid based $\mathrm{NPs}^{86}$ at both bright-field microscopy and TEM. ${ }^{87}$ Immunocytochemistry allowed detecting chitosan NPs loaded with a synthetic opioid at both FM and TEM, ${ }^{88}$ and this technique may simultaneously be performed with photo-oxidation. ${ }^{89}$

\section{Conclusions}

The great development of scientific research in nanomedicine resulted, especially in the last decade, in the extensive use of several imaging techniques to visualise the nanoconstructs in cells, tissues, organs or the whole organism. In vivo imaging techniques have the big advantage to make longitudinal studies possible and to allow monitoring the administration, biodistribution, accumulation and clearances of different kinds of nanocompounds. They have, however, different sensitivity and resolution: for example, MRI gives high resolution (in the order of $\mu \mathrm{m}$ ), anatomical information, and good soft-tissue contrast but has low sensitivity (in the order of $\mathrm{mM}$ ) compared to the nuclear-medicine imaging techniques (PET), that are highly sensitive (in the range of $\mathrm{pM}$ ) and quantitative, but suffer from a poor resolution (in the order of $\mathrm{mm}$ ). In the attempt to finely describe the interaction of the nanoconstructs with the cells' compartments, from the plasma membrane to the cytoplasmic organelles, the nucleus and the sub-nuclear domains, microscopy techniques and histochemistry proved to be crucial. In fact, the wide use of techniques at light and electron microscopy inspired a sort of Renaissance for many long-established morphological methods that, in the "omics era", had long been seen as merely descriptive. , $^{2,90,91}$ When applied to nanotechnology, these methods proved to be essential not only to understand the spatial relationships between the nanoconstructs and the biological environment, but also provided functional information, and were central to design efficient diagnostic or therapeutic strategies. In turn, the application of imaging techniques to the nanotechnological issues has led to adapt standard methods to special purposes and to originally develop new technical tools..$^{92-94}$

Undeniably, imaging techniques have significantly contributed to the development of nanotechnology in the biomedical field, thanks to the integration of apparently distant methodological approaches that enabled to get a comprehensive anatomical, histological and functional picture of the complex interactions the nanoconstructs exert with the living systems.

\section{References}

1. Weber DO. Nanomedicine. Health Forum J 1999;42:32:36-7.

2. Malatesta M. Transmission electron microscopy for nanomedicine: novel applications for long-established tech niques. Eur J Histochem 2016;60:2751.

3. Dearling JLJ, Packard AB. Molecular imaging in nanomedicine - A developmental tool and a clinical necessity. J Control Release 2017;261:23-30.

4. Rong G, Tuttle EE, Neal Reilly A, Clark HA. Recent developments in nanosensors for imaging applications in biological systems. Annu Rev Anal Chem 2019;12:109-28.

5. Wu K, Su D, Liu J, Saha R, Wang JP. Magnetic nanoparticles in nanomedicine: a review of recent advances. Nanotechnology 2019;30:502003.

6. Alizadeh D, Zhang L, Hwang J, Schluep T, Badie B. Tumorassociated macrophages are predominant carriers of cyclodextrin-based nanoparticles into gliomas. Nanomedicine 2010;6:382-90.

7. Zhou T, Jia X, Li H, Wang J, Zhang H, A Y, et al. New tumortargeted nanosized delivery carrier for oligonucleotides: characteristics in vitro and in vivo. Int $\mathrm{J}$ Nanomedicine 2011;6:1527-34.

8. Wang P, Qu Y, Li C, Yin L, Shen C, Chen W, et al. Bio-functionalized dense-silica nanoparticles for MR/NIRF imaging of CD146 in gastric cancer. Int J Nanomedicine 2015;10:749-63.

9. Vu-Quang H, Vinding MS, Nielsen T, Ullisch MG, Nielsen $\mathrm{NC}$, Kjems J. Theranostic tumor targeted nanoparticles combining drug delivery with dual near infrared and (19)F magnetic resonance imaging modalities. Nanomedicine 2016; 12:1873-84.

10. Van der Meer SB, Knuschke T, Frede A, Schulze N, Westendorf AM, Epple M. Avidin-conjugated calcium phosphate nanoparticles as a modular targeting system for the attachment of biotinylated molecules in vitro and in vivo. Acta Biomater 2017;57:414-25.

11. González-Gómez MA, Belderbos S, Yañez-Vilar S, Piñeiro Y, Cleeren F, et al. Development of superparamagnetic nanoparticles coated with polyacrylic acid and aluminum hydroxide as an efficient contrast agent for multimodal imaging. Nanomaterials (Basel) 2019;9:1626.

12. Esposito E, Cortesi R, Drechsler M, Fan J, Fu BM, Calderan L, et al. Nanoformulations for dimethyl fumarate: Physicochemical characterization and in vitro/in vivo behavior. Eur J Pharm Biopharm 2017;115:285-96.

13. Mannucci S, Calderan L, Quaranta P, Antonini S, Mosca F, Longoni B, et al. Quantum dots labelling allows detection of the homing of mesenchymal stem cells administered as immunomodulatory therapy in an experimental model of pancreatic islets transplantation. J Anat 2017;230:381-8.

14. Mannucci S, Boschi F, Cisterna B, Esposito E, Cortesi R, Nastruzzi C, et al. A correlative imaging study of in vivo and ex vivo biodistribution of solid lipid nanoparticles. Int $\mathrm{J}$ Nanomedicine 2020;15:1745-58.

15. Forte E, Fiorenza D, Torino E, Costagliola di Polidoro A, Cavaliere C, Netti PA, et al. Radiolabeled PET/MRI nanoparticles for tumor imaging. J Clin Med 2019;9. pii: E89.

16. Stride E, Segers T, Lajoinie G, Cherkaoui S, Bettinger T, Versluis M, Borden M. Microbubble agents: New directions. Ultrasound Med Biol 2020;46:1326-43.

17. Madru, R, Budassi, M, Benveniste, H, Lee, H, Smith, SD, Schlyer, DJ et al. Simultaneous preclinical positron emission tomography-magnetic resonance imaging study of lymphatic drainage of chelator-free $\mathrm{Cu}-64-$ labeled nanoparticles. Cancer Biother Radiopharm 2018;33:213-20. 
18. Yu EY, Bishop M, Zheng B, Ferguson BM, Khandhar AP, Kemp SJ, et al. Magnetic particle imaging: A novel in vivo imaging platform for cancer detection. Nano Lett 2017; 17:1648-54.

19. Mannucci S, Ghin L, Conti G, Tambalo S, Lascialfari A, Orlando $\mathrm{T}$, et al. Magnetic nanoparticles from Magnetospirillum gryphiswaldense increase the efficacy of thermotherapy in a model of colon carcinoma. PLoS One 2014;9:e108959.

20. Mannucci S, Tambalo S, Conti G, Ghin L, Milanese A, Carboncino A, et al. magnetosomes extracted from magnetospirillum gryphiswaldense as theranostic agents in an experimental model of glioblastoma. Contrast Media Mol Imaging 2018;2018:2198703.

21. Tay ZW, Chandrasekharan P, Chiu-Lam A, Hensley DW, Dhavalikar R, Zhou XY, et al. Magnetic particle imaging-guided heating in vivo using gradient fields for arbitrary localization of magnetic hyperthermia therapy. ACS Nano 2018;12:3699-713.

22. Deh K, Zaman M, Vedvyas Y, Liu Z, McCabe G, O’Malley P et al. Validation of MRI quantitative susceptibility mapping of superparamagnetic iron oxide nanoparticles for hyperthermia applications in live subjects. Sci Rep 2020;10:1171.

23. Rampazzo E, Boschi F, Bonacchi S, Juris R, Montalti M, Zaccheroni N, et al. Multicolor core/shell silica nanoparticles for in vivo and ex vivo imaging. Nanoscale 2012;4:824-30.

24. Moreno MJ, Ling B, Stanimirovic DB. In vivo near-infrared fluorescent optical imaging for CNS drug discovery. Expert Opin Drug Discov 2020;1-13.

25. Bruns OT, Bischof TS, Harris DK, Franke D, Shi Y, Riedemann L, et al. Next-generation in vivo optical imaging with short-wave infrared quantum dots. Nat Biomed Eng 2017;1:0056

26. Tapeinos C, Battaglini M, Ciofani G. Advances in the design of solid lipid nanoparticles and nanostructured lipid carriers for targeting brain diseases. J Control Release 2017;264:306-32.

27. Perera RH, Wu H, Peiris P, Hernandez C, Burke A, Zhang H, Exner AA. Improving performance of nanoscale ultrasound contrast agents using N,N-diethylacrylamide stabilization. Nanomedicine 2017;13:59-67.

28. Zhang Y, Zhang B, Liu F, Luo J, Bai J. In vivo tomographic imaging with fluorescence and MRI using tumor-targeted dual-labeled nanoparticles. Int J Nanomedicine 2014;9:33-41.

29. Konopka CJ, Wozniak M, Hedhli J, Ploska A, Schwartz-Duval A, Siekierzycka A, et al. Multimodal imaging of the receptor for advanced glycation end-products with molecularly targeted nanoparticles. Theranostics 2018;8:5012-24.

30. Tam J, Pilozzi A, Mahmood U, Huang X. Simultaneous monitoring of multi-enzyme activity and concentration in tumor using a triply labeled fluorescent in vivo imaging probe. Int J Mol Sci 2020;21. pii: E3068.

31. Wang Y, Chen C, Luo Y, Xiong J, Tang Y, Yang H, et al. Experimental study of tumor therapy mediated by multimodal imaging based on a biological targeting synergistic agent. Int $\mathrm{J}$ Nanomedicine 2020;15:1871-88.

32. Boschi F, Calderan L, D’Ambrosio D, Marengo M, Fenzi A, Calandrino $\mathrm{R}$, et al. In vivo ${ }^{18} \mathrm{~F}-\mathrm{FDG}$ tumour uptake measurements in small animals using Cerenkov radiation. Eur J Nucl Med Mol Imaging 2011;38:120-7.

33. Sulheim E, Kim J, van Wamel A, Eugene Kim, Snipstad S, Vidic I, et al. Multi-modal characterization of vasculature and nanoparticle accumulation in five tumor xenograft models. J Control Release 2018;279:292-305.

34. Chen F, Ehlerding EB, Cai W. Theranostic nanoparticles. J Nucl Med 2014;55:1919-22.
35. Qiu W, Chen R, Chen X, Zhang H, Song L, Cui W, et al. Oridonin-loaded and GPC1-targeted gold nanoparticles for multimodal imaging and therapy in pancreatic cancer. Int $\mathrm{J}$ Nanomedicine 2018;13:6809-27.

36. Kwak MH, Yi G, Yang SM, Choe Y, Choi S, Lee H-S, et al. A dodecapeptide selected by phage display as a potential theranostic probe for colon cancers. Transl Oncol 2020;13(9):100798.

37. Gawne PJ, Clarke F, Turjeman K, Cope AP, Long NJ, Barenholz Y, et al. PET imaging of liposomal glucocorticoids using 89Zr-oxine: Theranostic applications in inflammatory arthritis. Theranostics 2020;10:3867-79.

38. Nomani A, Haririan I, Rahimnia R, Fouladdel S, Gazori T, Dinarvand $\mathrm{R}$, et al. Physicochemical and biological properties of self-assembled antisense/poly(amidoamine) dendrimer nanoparticles: the effect of dendrimer generation and charge ratio. Int J Nanomedicine 2010;5:359-69.

39. Zhu XM, Wang YX, Leung KC, Lee SF, Zhao F, Wang DW, et al. Enhanced cellular uptake of aminosilane-coated superparamagnetic iron oxide nanoparticles in mammalian cell lines. Int J Nanomedicine 2012;7:953-64.

40. Patnaik S, Arif M, Pathak A, Kurupati R, Singh Y, Gupta KC Cross-linked polyethylenimine-hexametaphosphate nanoparticles to deliver nucleic acids therapeutics. Nanomedicine 2010;6:344-54.

41. Alukda D, Sturgis T, Youan BC. Formulation of tenofovir-loaded functionalized solid lipid nanoparticles intended for HIV prevention. J Pharm Sci 2011;100:3345-56.

42. Yang H, Lou C, Xu M, Wu C, Miyoshi H, Liu Y. Investigation of folate-conjugated fluorescent silica nanoparticles for targeting delivery to folate receptor-positive tumors and their internalization mechanism. Int J Nanomedicine 2011;6:2023-32.

43. Ricci V, Zonari D, Cannito S, Marengo A, Scupoli MT, Malatesta M, et al. Hyaluronated mesoporous silica nanoparticles for active targeting: influence of conjugation method and hyaluronic acid molecular weight on the nanovector properties. J Colloid Interface Sci 2018;516:484-97.

44. Avvakumova S, Galbiati E, Sironi L, Locarno SA, Gambini L, Macchi $\mathrm{C}$, et al. Theranostic nanocages for imaging and photothermal therapy of prostate cancer cells by active targeting of neuropeptide-y receptor. Bioconjug Chem 2016;27:2911-22.

45. Drijvers E, Liu J, Harizaj A, Wiesner U, Braeckmans K, Hens Z, Aubert T. Efficient endocytosis of inorganic nanoparticles with zwitterionic surface functionalization. ACS Appl Mater Interfaces 2019;11:38475-82.

46. Singh S. Glucose decorated gold nanoclusters: A membrane potential independent fluorescence probe for rapid identification of cancer cells expressing Glut receptors. Colloids Surf B Biointerfaces 2017;155:25-34.

47. Lei H, Hofferberth SC, Liu R, Colby A, Tevis KM, Catalano P, et al. Paclitaxel-loaded expansile nanoparticles enhance chemotherapeutic drug delivery in mesothelioma 3-dimensional multicellular spheroids. J Thorac Cardiovasc Surg 2015; 149:1417-24.

48. Gerstenhaber JA, Marcinkiewicz C, Barone FC, Sternberg M, D'Andrea MR, Lelkes PI, et al. Biocompatibility studies of fluorescent diamond particles-(NV) 800nm (part V): in vitro kinetics and in vivo localization in rat liver following longterm exposure. Int J Nanomedicine 2019;14:6451-64.

49. Tang H, Jiang Z, He H, Li X, Hu H, Zhang N, et al. Uptake and transport of pullulan acetate nanoparticles in the BeWo b30 placental barrier cell model. Int J Nanomedicine 2018;13: 4073-82.

50. Alnasser Y, Kambhampati SP, Nance E, Rajbhandari L, Shrestha S, Venkatesan A, et al. Preferential and increased 
uptake of hydroxyl-terminated PAMAM dendrimers by activated microglia in rabbit brain mixed glial culture. Molecules 2018;23:1025.

51. Liang H, Zhou B, He Y, Pei Y, Li B, Li J. Tailoring stimuliresponsive delivery system driven by metal-ligand coordination bonding. Int J Nanomedicine 2017;12:3315-30.

52. Koren E, Apte A, Jani A, Torchilin VP. Multifunctional PEGylated 2C5-immunoliposomes containing $\mathrm{pH}$-sensitive bonds and TAT peptide for enhanced tumor cell internalization and cytotoxicity. J Control Release 2012;160:264-73.

53. Yahia-Ammar A, Sierra D, Mérola F, Hildebrandt N, Le Guével $\mathrm{X}$. Self-assembled gold nanoclusters for bright fluorescence imaging and enhanced drug delivery. ACS Nano 2016;10(2):2591-9.

54. Guedj AS, Kell AJ, Barnes M, Stals S, Gonçalves D, Girard D, et al. Preparation, characterization, and safety evaluation of poly(lactide-co-glycolide) nanoparticles for protein delivery into macrophages. Int J Nanomedicine 2015;10:5965-79.

55. Kannan G, Kambhampati SP, Kudchadkar SR. Effect of anesthetics on microglial activation and nanoparticle uptake: Implications for drug delivery in traumatic brain injury. J Control Release 2017;263:192-9.

56. Azhdarzadeh M, Atyabi F, Saei AA, Varnamkhasti BS, Omidi Y, Fateh M, et al. Theranostic MUC-1 aptamer targeted gold coated superparamagnetic iron oxide nanoparticles for magnetic resonance imaging and photothermal therapy of colon cancer. Colloids Surf B Biointerfaces 2016;143:224-32.

57. Fiorentino I, Gualtieri R, Barbato V, Mollo V, Braun S, Angrisani A, et al. Energy independent uptake and release of polystyrene nanoparticles in primary mammalian cell cultures. Exp Cell Res 2015;330:240-7.

58. Das M, Duan W, Sahoo SK. Multifunctional nanoparticleEpCAM aptamer bioconjugates: a paradigm for targeted drug delivery and imaging in cancer therapy. Nanomedicine 2015;11:379-89.

59. Damalakiene L, Karabanovas V, Bagdonas S, Valius M, Rotomskis R. Intracellular distribution of nontargeted quantum dots after natural uptake and microinjection. Int $\mathrm{J}$ Nanomedicine 2013;8:555-68.

60. Wei Q, Huang C, Zhang Y, Zhao T, Zhao P, Butler P, et al. Mechanotargeting: Mechanics-dependent cellular uptake of nanoparticles. Adv Mater 2018;30:e1707464.

61. Correard F, Maximova K, Estève MA, Villard C, Roy M, A1Kattan A, et al. Gold nanoparticles prepared by laser ablation in aqueous biocompatible solutions: assessment of safety and biological identity for nanomedicine applications. Int $\mathbf{J}$ Nanomedicine 2014;9:5415-30.

62. Boyles MS, Kristl T, Andosch A, Zimmermann M, Tran N, Casals E, et al. Chitosan functionalisation of gold nanoparticles encourages particle uptake and induces cytotoxicity and pro-inflammatory conditions in phagocytic cells, as well as enhancing particle interactions with serum components. J Nanobiotechnology 2015;13:84.

63. Mohamed T, Matou-Nasri S, Farooq A, Whitehead D, Azzawi M. Polyvinylpyrrolidone-coated gold nanoparticles inhibit endothelial cell viability, proliferation, and ERK1/2 phosphorylation and reduce the magnitude of endothelial-independent dilator responses in isolated aortic vessels. Int J Nanomedicine 2017;12:8813-30.

64. Guarnieri D, Melone P, Moglianetti M, Marotta R, Netti PA, Pompa PP. Particle size affects the cytosolic delivery of membranotropic peptide-functionalized platinum nanozymes. Nanoscale 2017;9:11288-96.

65. Malatesta M, Giagnacovo M, Costanzo M, Conti B, Genta I, Dorati R, et al. Diaminobenzidine photoconversion is a suit- able tool for tracking the intracellular location of fluorescently labelled nanoparticles at transmission electron microscopy. Eur J Histochem 2012;56:e20.

66. Malatesta M, Grecchi S, Chiesa E, Cisterna B, Costanzo M, Zancanaro C. Internalized chitosan nanoparticles persist for long time in cultured cells. Eur J Histochem 2015;59:2492.

67. Costanzo M, Carton F, Marengo A, Berlier G, Stella B, Arpicco $\mathrm{S}$, et al. Fluorescence and electron microscopy to visualize the intracellular fate of nanoparticles for drug delivery. Eur J Histochem 2016;60:2640.

68. Liu Y, He M, Niu M, Zhao Y, Zhu Y, Li Z, et al. Delivery of vincristine sulfate-conjugated gold nanoparticles using liposomes: a light-responsive nanocarrier with enhanced antitumor efficiency. Int J Nanomedicine 2015;10:3081-95.

69. Costanzo M, Scolaro L, Berlier G, Marengo A, Grecchi S, Zancanaro C, et al. Cell uptake and intracellular fate of phospholipidic manganese-based nanoparticles. Int $\mathrm{J}$ Pharm 2016;508:83-91.

70. Perez JE, Contreras MF, Vilanova E, Felix LP, Margineanu MB, Luongo G, et al. Cytotoxicity and intracellular dissolution of nickel nanowires. Nanotoxicology 2016;10:871-80.

71. Siow WX, Chang YT, Babič M, Lu YC, Horák D, Ma YH. Interaction of poly-1-lysine coating and heparan sulfate proteoglycan on magnetic nanoparticle uptake by tumor cells. Int $\mathrm{J}$ Nanomedicine 2018;13:1693-706.

72. Marinozzi MR, Pandolfi L, Malatesta M, Colombo M, Collico $\mathrm{V}$, Lievens PM, et al. Innovative approach to safely induce controlled lipolysis by superparamagnetic iron oxide nanoparticles-mediated hyperthermic treatment. Int $\mathrm{J}$ Biochem Cell Biol 2017;93:62-73.

73. Costanzo M, Vurro F, Cisterna B, Boschi F, Marengo A, Montanari E, et al. Uptake and intracellular fate of biocompatible nanocarriers in cycling and noncycling cells. Nanomedicine (Lond) 2019;14:301-16.

74. Guglielmi V, Carton F, Vattemi G, Arpicco S, Stella B, Berlier $\mathrm{G}$, et al. Uptake and intracellular distribution of different types of nanoparticles in primary human myoblasts and myotubes. Int J Pharm 2019;560:347-56.

75. Codullo V, Cova E, Pandolfi L, Breda S, Morosini M, Frangipane V, et al. Imatinib-loaded gold nanoparticles inhibit proliferation of fibroblasts and macrophages from systemic sclerosis patients and ameliorate experimental bleomycininduced lung fibrosis. J Control Release 2019;310:198-208.

76. Dejardin T, de la Fuente J, del Pino P, Furlani EP, Mullin M, Smith CA, et al. Influence of both a static magnetic field and penetratin on magnetic nanoparticle delivery into fibroblasts. Nanomedicine (Lond) 2011;6:1719-31.

77. Skopalik J, Polakova K, Havrdova M, Justan I, Magro M, Milde D, et al. Mesenchymal stromal cell labeling by new uncoated superparamagnetic maghemite nanoparticles in comparison with commercial Resovist - an initial in vitro study. Int J Nanomedicine 2014;9:5355-72.

78. Jenkins SI, Roach P, Chari DM. Development of a nanomaterial bio-screening platform for neurological applications. Nanomedicine 2015; 11:77-87.

79. Abedin MR, Umapathi S, Mahendrakar H, Laemthong $\mathrm{T}$, Coleman H, Muchangi D, et al. Polymer coated gold-ferric oxide superparamagnetic nanoparticles for theranostic applications. J Nanobiotechnology 2018;16:80.

80. England CG, Priest T, Zhang G, Sun X, Patel DN, McNally LR et al. Enhanced penetration into $3 \mathrm{D}$ cell culture using two and three layered gold nanoparticles. Int $\mathrm{J}$ Nanomedicine 2013;8:3603-17.

81. Chen R, Yu H, Jia ZY, Yao QL, Teng GJ. Efficient nano iron particle-labeling and noninvasive MR imaging of mouse bone 
marrow-derived endothelial progenitor cells. Int $\mathrm{J}$ Nanomedicine 2011;6:511-9.

82. Zhang L, Gong F, Zhang F, Ma J, Zhang P, Shen J. Targeted therapy for human hepatic carcinoma cells using folate-functionalized polymeric micelles loaded with superparamagnetic iron oxide and sorafenib in vitro. Int $\mathrm{J}$ Nanomedicine 2013;8:1517-24.

83. Cicha I, Scheffler L, Ebenau A, Lyer S, Alexiou C, GoppeltStruebe M. Mitoxantrone-loaded superparamagnetic iron oxide nanoparticles as drug carriers for cancer therapy: Uptake and toxicity in primary human tubular epithelial cells. Nanotoxicology 2016;10:557-66.

84. Jiang W, Lai K, Wu Y, Gu Z. Protein corona on magnetite nanoparticles and internalization of nanoparticle-protein complexes into healthy and cancer cells. Arch Pharm Res 2014;37:129-41.

85. Malatesta M, Pellicciari C, Cisterna B, Costanzo M, Galimberti $\mathrm{V}$, Biggiogera $\mathrm{M}$, et al. Tracing nanoparticles and photosensitizing molecules at transmission electron microscopy by diaminobenzidine photo-oxidation. Micron 2014;59:44-51.

86. Carton F, Chevalier Y, Nicoletti L, Tarnowska M, Stella B, Arpicco S, et al. Rationally designed hyaluronic acid-based nano-complexes for pentamidine delivery. Int $\mathrm{J}$ Pharm 2019;568:118526.

87. Carton F, Repellin M, Lollo G, Malatesta M. Alcian blue staining to track the intracellular fate of hyaluronic-acid-based nanoparticles at transmission electron microscopy. Eur J
Histochem 2019;63:3086.

88. Malatesta M, Galimberti V, Cisterna B, Costanzo M, Biggiogera M, Zancanaro C. Chitosan nanoparticles are efficient carriers for delivering biodegradable drugs to neuronal cells. Histochem Cell Biol 2014;141:551-8.

89. Malatesta M, Zancanaro C, Costanzo M, Cisterna B, Pellicciari C. Simultaneous ultrastructural analysis of fluorochrome-photoconverted diaminobenzidine and gold immunolabelling in cultured cells. Eur J Histochem 2013;57:e26.

90. Pellicciari C, Malatesta M. Identifying pathological biomarkers: Histochemistry still ranks high in the omics era. Eur J Histochem 2011;55:e42.

91. Busato A, Fumene Feruglio P, Parnigotto PP, Marzola P, Sbarbati A. In vivo imaging techniques: a new era for histochemical analysis. Eur J Histochem 2016;60:2725.

92. Scimeca M, Bischetti S, Lamsira HK, Bonfiglio R, Bonanno E. Energy dispersive X-ray (EDX) microanalysis: A powerful tool in biomedical research and diagnosis. Eur J Histochem 2018;62:2841.

93. Costanzo M, Malatesta M. Embedding cell monolayers to investigate nanoparticle-plasmalemma interactions at transmission electron microscopy. Eur J Histochem 2019;63:3026.

94. Falsini S, Tani C, Schiff S, Gonnelli C, Clemente I, Ristori S, et al. A new method for the direct tracking of in vivo lignin nanocapsules in Eragrostis tef (Poaceae) tissues. Eur J Histochem 2020;64:3112.

Received for publication: 15 June 2020. Accepted for publication: 22 June 2020.

This work is licensed under a Creative Commons Attribution-NonCommercial 4.0 International License (CC BY-NC 4.0).

(C) Copyright: the Author(s), 2020

Licensee PAGEPress, Italy

European Journal of Histochemistry 2020; 64:3151

doi:10.4081/ejh.2020.3151 